\title{
Game Based Learning as a Promoter for Positive Health Behaviours in Young People
}

Andrew Sean Wilson

School of Computing, Telecommunications and Networks. Faculty of Technology, Engineering and the Environment. Birmingham City University, Millennium Point, Curzon Street, Birmingham. B4 7XG. UK.

\section{EXECUTIVE SUMMARY}

Maintaining the healthcare of young people living with long term medical conditions is dependent upon them acquiring a range of self-care skills. Encouraging them to attain these as well as assessing their competency in them beyond the healthcare setting is challenging. The development of educational computer games like Health Heroes, Re-Mission and Sparx have been shown to successfully improve self-care, communication and adherence to medicines in young patients. Therefore this medium might be an alternative means for delivery of healthcare information. In this chapter we propose that by encapsulating healthcare processes in game based learning (GBL) either by computer games or by applying the principles of gamification a more fun; structured and objective process would be created and one in which young people can relate to. The framework we suggest will provide doctors with an insight into how GBL could be used positively in a healthcare setting as well as provide a basis for application to other disciplines where knowledge and skills acquisition can be challenging.

\section{BACKGROUND}

Many people are now expected to live longer than in previous generations. With this increase in life expectancy the incidence of age-associated long term illness is also predicted to rise (WHO, 2013). Nearly 133 million Americans (Bodenheimer, Chen, \& Bennett, 2009) and 15 million United Kingdom (UK) citizens ( $\mathrm{DoH}, 2011)$ live with a long term medical condition. Two thirds of all deaths in the USA are attributable to conditions such as cancer, diabetes, lung disease, heart disease or stroke ("Tackling the burden of chronic diseases in the USA", 2009). In the UK mental and behavioural disorders (including substance abuse) and musculoskeletal conditions are some of the major causes of long term disability. Long term medical conditions are not restricted to the elderly; young people may also experience conditions such as cancer, asthma, diabetes, cystic fibrosis, heart disease or (juvenile) arthritis. Approximately $14 \%$ of young people in the UK live with a long term medical condition (Hagell, Coleman, \& Brooks, 2013).

As young people grow older patterns of health promoting as well as health risk behaviours are established which can be maintained throughout their life (Sawyer, Drew, Yeo, \& Britto, 2007). Activities such as unhealthy diet, drugs and alcohol misuse, smoking, physical inactivity, and unsafe sexual practices can lead to poor health outcomes (Murray et al., 2013). If a young person is already living with a long term illness engaging in health risk behaviours can further complicate their condition. Smoking can accelerate the development of heart disease in diabetics (Grundy et al., 1999); alcohol can enhance the toxicity of 
medications (Nash, Britto, Lovell, Passo, \& Rosenthal, 1998) whereas drug therapies can affect fertility and can potentially cause birth defects (Janssen \& Genta, 2000). Research has shown that health risk behaviours can be more common in young people with long term conditions with greater potential for adverse health outcomes in them (Sawyer at al., 2007; Suris, Michaud, Akre, \& Sawyer, 2008; Philpott, 2011).

Care for a young person with a long term medical condition is on-going and ideally will adapt to their needs as they grow older. If they are diagnosed during childhood their care will be in an environment which is focused towards theirs and their family's needs. Their condition may persist over time and even follow them into their adult life. This means that they will eventually have to transfer to the adult healthcare system which is very different from that which they were used to as a child. In the UK this normally occurs between 16 and 18 years of age but is more dependent upon local policy rather than the young person's confidence in being able to cope in the new setting. Transfer can be a cause of anxiety to both the young person and their family as they will have to experience a new healthcare environment. If the transfer is not managed appropriately there is an increased chance that the young person will "drop out" of the healthcare system (Wacker et al., 2005; Yeung, Kay, Roosevelt, Brandon, \& Yetman, 2008), risking poorer health outcomes (Annunziato et al., 2007) and subsequently be re-admitted to hospital (Yeung et al., 2008; Nakhla, Daneman, To, Paradis, \& Guttmann, 2009).

In order to maintain the continuity of a young person's care careful and purposeful planned preparation for transfer is important (McDonagh, 2007), this is known as transitional care. It addresses the medical, psychosocial, educational and vocational needs of the young person in an age and developmentally appropriate manner. As the young person matures the responsibilities for their care moves away from the parent requiring the young person to acquire a range of knowledge and skills that are important for them to function independently in the adult healthcare system. These include understanding of health and condition specific issues, self-management skills, effective information-seeking skills, managing psychological and general health, effectively utilising the healthcare available to them, coping with social issues, maintaining their education and vocation aspirations as well being able to live independently.

Adolescence (10-19 years of age (WHO, 2001)) is considered to be one of the most sensitive developmental periods next to early childhood (Viner et al., 2012) Therefore this is a time when positive health behaviours can be influenced and where preventative healthcare strategies should be focused (Catalano et al., 2012). Educational resources to support the needs of young people's healthcare are very important but many patients and their families find it difficult to get the information they need and it is not always in appropriate style for them (Shaw, Southwood, \& McDonagh, 2004). There is interest in how information can be presented in a youth friendly way and how technology can be used to support this (Stinson et al., 2008). It has been proposed that new forms of communication which are used and enjoyed by young people such as social marketing, creative design and information technology should be taken advantage of to assist them with their varying developmental and disease-related needs (Sawyer et al. 2007; Sawyer et al., 2012). The Internet has established itself as a major source of health information and a medium that young people often use in order to answer their queries (Suris, Akré, Berchtold, Bélanger, $\&$ Michaud, 2010). Their involvement has seen the development of dedicated youth-centred online healthcare programmes. These have included interactive activities, self-monitoring and reflection, youthto-youth information sharing and social support, and accurate, accessible and developmentally targeted health specific information (Scal, Garwick, \& Horvath, 2010). 
In 2012 a report by the entertainment software association (ESA, 2013) showed that 32\% of Americans who played video games were less than 18 years of age and in Europe 26\% of gamers were under 24 years of age (Interactive Software Federation of Europe, 2012). Computer games therefore form an important part of young people's lives and could be used as a way of engaging them in learning how to take care of themselves.

The use of computer games as an educational medium is of increasing interest because their inherent characteristics give players unique personal perspectives and experiences. The mechanics that define how the game works and is played, for example use of goals, challenges, rewards, competition and feedback, can be used to positively reinforce learning. Therefore computer games offer the potential for creating educational environments that are fun and can facilitate active participation in learning as the players can construct knowledge at their own pace and under their control. However negative connotations have been associated with playing computer games for example increasing sedentary behaviour and their potential to increase antisocial and aggressive behaviours in young people (Janssen, Boyce, \& Pickett, 2012; Ferguson, Miguel, Garza, \& Jerabeck, 2012).

Despite this computer games have been used to educate young people about healthcare issues but there is very little work in its application to issues that are associated with transitional care. In this chapter we will discuss how I (as the technologist) and my colleague Dr. Janet McDonagh (a clinician and specialist in adolescent care) from Birmingham Children's Hospital (BCH) in the UK have been exploring how game based learning (GBL) could be used to provide important healthcare information to young people.

In this chapter we will discuss the research we have been conducting in how GBL could be used in healthcare for young people. This includes a review of some of the computer games which have been designed to help young people with long term medical conditions. We will also discuss the importance of using appropriate assessments as a way of measuring health outcomes as well as how game mechanics could be used to support the acquisition of self-care and self-management skills. We will also highlight the issues and concerns by the healthcare services associated with young people using technology and computer games.

\section{SETTING THE STAGE}

Young people may be diagnosed with a long term medical condition early in their life. As they grow older their healthcare needs will change. Gauging when a young person is ready to transfer their healthcare depends upon the young person's self-belief, involvement of their parents and the healthcare team. This approach is subjective which has resulted in the development of several assessment tools aimed at helping measure the range of skills which have been identified as being important for successful transfer of care (Sawicki et al., 2011; Ferris et al., 2012). Many of the items in these assessments are common to one another for example understanding the condition and its treatment, how to self-care, how to communicate with the healthcare team and understanding how to use support services. However these assessments may be disease specific and have aspects that are more relevant to their country of origin for example dealing with medical insurance and the financial aspects of healthcare.

A series of healthcare plans and transitional readiness checklists which reflect the developmental stages of adolescence, ("Getting Ready" - early adolescence, "Moving Along" - mid adolescence and "Moving Up" - late adolescence) have been developed by BCH's Adolescent Rheumatology Team and are more 
appropriate to the needs of young people in the UK. These were initially developed as part of a national multi-centre transitional care research project (McDonagh, Southwood, \& Shaw, 2006) and although they are not formally validated (a measure of dependability) they continue to be used with all young people attending the adolescent rheumatology service from age 11 years irrespective of condition. The checklists have evolved in response to the young people's requests which include the need to include statements regarding pain, fatigue and anger management. The checklists have eight domains which encompass knowledge, self-advocacy (speaking up for oneself), transferring to the adult healthcare system, health and lifestyle, activities of daily living, school and vocation, leisure as well as managing emotions. Figure 1 provides examples of the early and late adolescent checklist which the young person completes based upon their confidence in being able to perform the given task. The level of required knowledge and understanding that the plans assess increases as the young person matures.

\section{[Insert Figure 1 here]}

Figure 1. BCH Adolescent Rheumatology Team transitional readiness checklists for young people. The checklists show a range of tasks within the domains of knowledge, health and lifestyle for early and late adolescence. The items are used to gauge the level of increasing knowledge, understanding and skill acquisition as the young person matures.

Complementing the patient checklists is a doctor's checklist (Figure 2). This records the young person's progress in acquiring these skills as they grow older. The views of the young person always take precedence over the views of the clinical team.

[Insert Figure 2 here]

Figure 2. BCH Adolescent Rheumatology Team transitional readiness checklists for doctors. The checklist illustrates four of the domains (knowledge, self-advocacy, transfer to adult care and health and lifestyle).The doctor will record the progress of acquisition of knowledge and skills as the young person develops through early (E), mid (M) and late (L) adolescence.

\section{CASE DESCRIPTION}

\section{Review of Existing Healthcare Games for Young People}

Our initial research focussed on assessing existing games for young people with long term medical conditions. Websites such as social impact games (http://www.socialimpactgames.com) and games for change (http://www.gamesforchange.org) indicated that several had been produced however there was little evidence that the games had been evaluated for their effectiveness. Subsequently a review of the literature was conducted using Thomas Reuters' Web of Knowledge (http://wok.mimas.ac.uk) and Elsvier's Science Direct (http://www.sciencedirect.com). The search terms used included serious games, 
computer games for health, computer games and adolescence, computer games and young people. The results indicated that several games had been devised to help young people in a range of health issues and they had been evaluated to assess their effectiveness. The Health Hero (Bronkie the Bronchiasaurus, Captain Novolin, Packy \& Marlon and Rex Ronan - Experimental surgeon ) series of games were developed in the late 1990's. Bronkie the Bronchiasaurus is an adventure game for young people with asthma. The premise of the game is for players to keep two dinosaur characters (Bronkie and Trakie) in good health by monitoring their breathing, making sure that they take their medicines, correctly use their inhalers and avoid environmental triggers of asthma attacks. In Captain Novolin the player controls the aforementioned hero who must defeat alien invaders (in the form of junk food) and rescue the diabetic mayor in the game. During the game Captain Novolin must eat healthy meals in order to maintain safe blood glucose levels otherwise he may die. Bonus points can be earned by players if they correctly answer questions about diabetes. Packy \& Marlon was designed to help young people improve their selfmanagement of diabetes. The adventure game involves playing Packy \& Marlon, two diabetic elephants, who must find missing food and diabetic supplies which were scattered through the game by the enemy characters (rats and mice). The players must keep Packy \& Marlon's diabetes under control by managing their blood glucose levels, taking their medication (insulin) as well maintaining a balanced diet. Rex Ronan - Experimental surgeon (smoking prevention) involves taking control of a character that has been miniaturised and entered into a human body. By using his weapons (laser scalpel) he must remove the adverse effects of smoking (tar, phlegm, plaque, debris, and precancerous cells) from the patient. During the game the player must answer questions about the side effects of tobacco smoking. Research into the use of these games showed that young people who played them improved their knowledge, selfmanagement, perceived self-efficacy and communication with family and friends. These games were developed for the Super Nintendo Entertainment System (SNES) consoles and Microsoft Windows 95 but are no longer available.

More recent games such as Re-Mission (http://www.re-mission.net) and Re-Mission 2 (http://www.remission2.org) have been designed to help young people understand childhood cancers and their treatment (Figure 3).

[Insert Figure 3 here]

Figure 3. Screenshots of the original Re-Mission [A] game and NanoBotsRevenge from Re-Mission2 [B]. (C2013 HopeLab. Used with permission).

In Re-Mission the player controls a nanobot character called Roxxi who has been injected into a patient's body. The player must monitor the patient's health while trying to defeat various forms of cancer. The game is split into levels which have information on drug treatments, how they work and the importance of adhering to them. Re-Mission2 is a series of free online games (Nanobot's revenge, Stem Cell Defender, Nano Dropbot, Leukemia, Feeding Frenzy and Special Ops) which deal with a range of issues associated with childhood cancers and their treatment.

Sparx (http://sparx.org.nz) is a fantasy game designed for cognitive behavioural therapy (a psychological technique aimed at helping people change their behaviours) in order to help young people who are suffering from depression. The 3D game requires the player to take control of an avatar and compete in a series of challenges designed to restore the balance in the game world which is dominated by gloomy negative automatic thoughts (GNATs). 
Both Re-Mission and Sparx have been the subject of clinical trials where their effectiveness has been tested with young people who were living with the conditions. Re-Mission has been shown to improve cancer related knowledge, self-efficacy and adherence to drug treatments (Beale, Kato, Marin-Bowling, Guthrie, \& Cole, 2007; Kato, Cole, Bradlyn, \& Pollock, 2008) whereas Sparx reduced depression, anxiety, hopelessness and improved the quality of life (Merry et al., 2012). Innovative games such as Creep Frontier, a game to help young people with cystic fibrosis, incorporates the use of a spirometer (a tool to measure the volume of air that a person breathes in and out) into the game in order to train the young player how to use it (Bingham, Bates, Thompson-Figueroa, \& Lahiri, 2010). Table 1 summarises games that have been produced and formally evaluated with indication of their outcomes. 
Table 1. Examples of computer games for healthcare in young people.

\begin{tabular}{|c|c|c|c|c|c|c|c|}
\hline & $\begin{array}{l}\text { Rex Ronan - } \\
\text { Experimental } \\
\text { surgeon* }\end{array}$ & $\begin{array}{c}\text { Bronkie the } \\
\text { Bronchiasaurus * }\end{array}$ & $\begin{array}{l}\text { Packy \& } \\
\text { Marlon * }\end{array}$ & $\begin{array}{c}\text { Captain } \\
\text { Novolin } *\end{array}$ & Re-Mission & $\begin{array}{l}\text { Creep } \\
\text { Frontier }\end{array}$ & Sparx \\
\hline Study author(s) & $\begin{array}{l}\text { Lieberman \& } \\
\text { Brown, } 1995\end{array}$ & Lieberman, 1997 & $\begin{array}{l}\text { Brown et } \\
\text { al., } 1997\end{array}$ & $\begin{array}{c}\text { Lieberman, } \\
1997\end{array}$ & $\begin{array}{c}\text { Beale et al., } \\
\text { 2007; Kato et } \\
\text { al., } 2008\end{array}$ & $\begin{array}{l}\text { Bingham et } \\
\text { al., } 2010\end{array}$ & $\begin{array}{c}\text { Merry et al., } \\
2012\end{array}$ \\
\hline $\begin{array}{l}\text { Aspect of health } \\
\text { covered in game }\end{array}$ & $\begin{array}{l}\text { Smoking } \\
\text { prevention }\end{array}$ & Asthma & Diabetes & Diabetes & Cancer & $\begin{array}{l}\text { Cystic } \\
\text { Fibrosis }\end{array}$ & Depression \\
\hline $\begin{array}{l}\text { Improved knowledge } \\
\text { about subject }\end{array}$ & $\checkmark$ & $\checkmark$ & & & $\checkmark$ & $\checkmark$ & \\
\hline $\begin{array}{l}\text { Improved self-efficacy } \\
\text { and self-management }\end{array}$ & & $\checkmark$ & $\checkmark$ & & $\checkmark$ & & \\
\hline $\begin{array}{l}\text { Improved } \\
\text { communication skills }\end{array}$ & & $\checkmark$ & $\checkmark$ & $\checkmark$ & & & \\
\hline $\begin{array}{l}\text { Improved adherence to } \\
\text { drug treatments. }\end{array}$ & & & & & $\checkmark$ & & \\
\hline $\begin{array}{l}\text { Improved health } \\
\text { outcomes }\end{array}$ & & & & & & & $\checkmark$ \\
\hline $\begin{array}{l}\text { Improved quality of } \\
\text { life }\end{array}$ & & & & & & & $\checkmark$ \\
\hline $\begin{array}{l}\text { Decreased visits to } \\
\text { doctor }\end{array}$ & & & $\checkmark$ & & & & \\
\hline
\end{tabular}

* Information about game can be found at http://www.socialimpactgames.com 
The Health Hero games were innovative in their approach to educating young people about their health by taking advantage of new and emerging recreational media and applying it to serious issues. The games allowed the player to explore worlds and interact with them; tested their understanding of their medical condition and provided a way to discuss issues with friends, family and the healthcare team (Lieberman, 1997). The principles (game mechanics) used in them occur in the other games we have review too. The mechanics used include goals, feedback, achievements and rewards, challenges and curiosity. These combine to give the young person incentives to work towards attaining knowledge about their health and self-care skills. They can also measure how well they are attaining the skills and highlights their achievements. As a result the games' designs encourage young people to participate in learning about their healthcare.

The improvements in knowledge, self-efficacy, self-management skills and adherence to treatment (Table 1) form important parts of transitional care. However the games reviewed are often disease specific (asthma, cancer and diabetes), focus on a set of required behaviours for that condition and may target particular age groups. Consequently they cannot be generalised to a range of long term medical conditions. Developing a game for transitional care is further complicated as the behaviours and levels of knowledge and skills required need to take into account the different stages of adolescence and the maturity of the young person.

The challenge of developing a game for healthcare involves designing it so that it is fun to play and engages its audience. It also has to increase the player's knowledge and positively influence their behaviours. Whether these have been achieved depends upon assessing the outcomes. Assessments may be embedded within the game which provides real-time feedback but this subsequently restricts the flexibility of the type of assessment and also limits its modification or adaptation as the assessment is locked into the game. Assessment may also be implemented outside of the game for example in the form of satisfaction surveys or knowledge quizzes. The latter often use pre and a post-test evaluation where the player is asked to complete a quiz prior to playing the game and then they complete another one after playing it. This is used to indicate whether the intervention (the game) has improved the person's understanding of the subject. Ideally the quiz would be repeated at a later date to see if the knowledge is retained over time.

Trying to embed all the requirements for a good healthcare game could be a challenge and time consuming process. However game mechanics can be applied in non-game contexts which is known as gamification.

\section{Game Mechanics and Gamification}

Gamification has been used in training, education, project management, social networks, health and wellness and in the commercial sector where it has been used in marketing and promotion with a view to engaging customers in product, service and brand loyalty. Examples include IBM connections where gamification has been posited as having the capability to improve organizational performance through a process of improving business collaborations (Royle, 2012). RedCritter Tracker (http://www.redcritter.com/company.aspx) is a project management tool for agile software development where team members can unlock badges and earn points for completing challenging tasks which can then be traded in for rewards in virtual stores. This approach is thought to improve both individual and team motivation and productivity. Nike Training club (http://www.nike.com/us/en_us/c/womens- 
training/apps/nike-training-club) is a mobile app which uses gamification to promote both physical activity and healthy lifestyle.

The BCH Adolescent Rheumatology Team healthcare checklists monitor progress from both the young person's and doctor's perspectives but is qualitative in nature. The process also relies on the intrinsic motivation of the young person to complete the tasks. Using the principles of gamification a quantitative measure of achievement and progress can be implemented and provides a mechanism for feedback. Figure 4 provides a conceptual framework where leader boards and rewards are integrated into the doctor's checklist.

[Insert Figure 4 here]

Figure 4. Leader board and rewards. By completing items within adolescent stages i.e. early (E), Mid (M) or Late (L) the player would gain points and badges for achievements which signify levels of experience. Trophies signify successful mastery of the domain. The knowledge leader board measures progress relative to that domain and feeds into the main leader board.

Each domain in the BCH Adolescent Rheumatology Team doctor's checklist (Figure 2) has a series of items associated with it and the response to each may be more demanding based upon the stage of adolescence that the young person is in. The response to each item at each stage of adolescence would have a score associated with it. In Figure 4 there are seven items based upon knowledge and up to three different levels based upon the stage of adolescence (early, mid or late). An example of how gamification may be applied is that each of the responses may have 100 points for each successfully completed item (a total of 2000 points for the domain). If the player completes all items associate with early adolescence they would receive 600 points and they would gain a level. More points and higher levels would be achieved as more knowledge is accumulated as the young person matures through the stages of adolescence. When all items within a domain are completed (2000 points and achieving level 3) a further reward can be earned signifying mastery of that domain. Some of the items in the checklists (Figure 2) lend themselves to aggregation, for example the young person being able to accurately describe their condition as well as the effects it has on their body or that the young person understands their medication and the potential side effects of it. Acquiring these skills in combination lend themselves to the assignment of bonuses points for successfully achieving both of them. Failure to attend clinical appointments is a common problem. Awarding bonus points for successfully attending them would help to reinforce their importance and encourage the young person to stay in the healthcare system.

Gamification uses rewards as a way of recognising achievements however it is important not to over use them as this could potentially devalue them conversely if insufficient are used the incentive to engage with the process can be lost. Reward schedule and ratios are used to manage this process with randomness and surprises enhancing the effectiveness.

Highlighting a player's achievement can be managed by recording their scores on a leader board which will also provide them with feedback on their overall progress relative to their peers. Leader boards have the potential to motivate or de-motivate the player if they feel the goals are unachievable. Marczewski (2013) suggests the use of both relative and absolute leader boards. Relative leader boards would indicate the players progress against their peers, within a domain, where as the absolute leader board would 
indicate overall performance, relative to their peers, in acquiring all the skills associated with successful transition.

Status is an important mark of achievement in games and also provides an opportunity to identify where new players can find help. In our system this provides an opportunity to identify mentors who can provide advice and support. The right to privacy and confidentiality is important when dealing with young people with medical conditions. Anonymity can be preserved by the use of online characters (avatars) that reflect their persona but hide their identity.

Monitoring the engagement of young people in this system is an important consideration. Gamification often uses web based applications and measures engagement by unique visitors, page views per visitor, time spent on site, total time spent per user, frequency and depth of visits, participation and conversions. These metrics cannot measure knowledge and skill acquisition and are less useful to the healthcare team. Therefore user generated content (UGC) such as the player keeping blogs, diaries, and uploading videos demonstrating their accomplishment of activities as well as participating in answering questions in on line forums may be a better indicator of participation.

\section{Management and Organizational Concerns}

Technology has become an important part of our world contributing to advancements in business and commerce, education as well as healthcare. However there are concerns that its (over)use in young people may be detrimental to their well-being particularly within the healthcare community. Computer games have been the focus of a lot of attention regarding negative behaviour associated with their use for example its relation to violent behaviour (Janssen, Boyce, \& Pickett, 2012) although research in this area highlights quite contradictory findings (Ferguson et al., 2012). One study has associated video game playing with less time being devoted to academic studies however the authors highlight this cannot be taken as an indicator of the person's academic achievements (Cummings \& Vandewater, 2007). Gentile et al., (2011) indicate that excessive video gaming can be related to poor psychosocial outcomes in some young people whereas earlier studies found no such effects the authors suggesting that video game playing is a healthy part of adolescence (Durkin \& Barber, 2002). A review by Hagell (2012) on the health implications of new technology describes both positive and negative aspects of its use with the suggestion that new technologies should form an important component in health promotion particularly in hard-to-reach groups. New and innovative ways of using technology should be found as a way of communicating with young people and delivering their services; focus being on taking full advantage of this media rather than avoiding it.

Promoting and demonstrating what can be achieved with technology has been one way that we have found that helps to break down the barriers and resistance to its adoption by the healthcare community. Ultimately we have to take into consideration the views of the young people and which media they would like to use which also means recognising that not all young people will want to use technology or computer games as their preferred source of information. Therefore alternatives need to be made available. Where computer games are to be considered as a means for educating young people sensible guidelines for their use should be provided which would allay some of the concerns of the doctors. 


\section{CURRENT CHALLENGES}

Transitional care is a complex process involving young people acquiring and maintaining a range of knowledge and skills which will vary with the age and maturity. Maintaining a young person's engagement in their healthcare is challenging as other factors increasingly become prominent in their (adolescent) lives. However the implications of not taking care of themselves are a poorer quality of life and delayed transfer to the adult healthcare system. Creating a process that allows both the young person and the doctor to monitor progress and create incentives for maintaining care in a fun way and which the young person can relate to would be advantageous. Using GBL could be one solution to this.

Inherently all games should be fun to play but in terms of GBL there is the requirement for sound pedagogy that will result in measurable and discernable learning outcomes. For GBL to be successful in the healthcare setting the game should also result in positive health outcomes too. Our initial research indicated that not all games being developed were following this approach with little evidence for evaluation of their effectiveness.

Designing games is an art rather than resulting from a prescribed formula. Our research highlighted the lack of any guidelines for developing healthcare games requiring us to work towards devising our own framework for game(s) for transitional care.

The resources for developing games are also a factor that needs to be taken into consideration. Computer games take time, money and skilled technical individuals in order to make them. The Health Hero games were early examples of how new technologies (games consoles) were being used to provide healthcare information in a format that young people could relate to and engage with. As technology moves very quickly there is the danger that it soon becomes out of date and while the information Health Heroes contains is relevant it is in a format that is no longer readily accessible.

When considering the format of GBL its cost - benefit and longevity needs to be taken into account. This led us to consider of the use of gamification where the fun elements of games and their mechanics may be used to enhance young people's engagement with their healthcare but where the technology required is not as sophisticated as would be required with the development of a computer game. Services such as Badgeville (http://badgeville.com/) and gamificationU (http:/gamificationu.com/) already provide resources to start creating gamified systems.

It is not to be underestimated that generating a system based upon gamification would still be a challenging and time consuming process. This would result from the implementation and refinement of a range of complex mechanics and balancing them to in order to make the game fair and fun to play with the added necessity to educate the player and positively influence their behaviour. There would also be the requirement to make sure appropriate assessments were incorporated in order to provide meaningful feedback to the players (patients) and doctors. By using this approach to develop a GBL system those game mechanics which are found to be effective in engaging the players in their healthcare process could then be candidate mechanics for incorporation into subsequent computer game(s).

Engagement in GBL may be dependent upon age and stage of development with younger people more likely to enjoy and participate in them. There is also the element of novelty, the challenges faced in order to maintain that game's uniqueness and how different genders perceive and react to it. Therefore there is 
the possibility it may only be effective within a certain time frame. As the system is a game and based upon achievements there is always the chance that people will try to cheat in order to gain the rewards which would be counter productive to the requirement that the young people are learning a set of behaviours which are important to their healthcare.

\section{SOLUTIONS AND RECOMMENDATIONS}

It is now accepted that young people are a distinct group with specialist healthcare needs which are quite distinct from children and adults. Medicine is a discipline which is keen to embrace technology to assist in patient care but may not be as fast to adopt as other sectors. Therefore our work is in its early stages.

We feel that designing GBL to support young people in transitional care will be dependent on understanding their needs and requirements for example acceptance of its use by them, what ages, stages of adolescent development and genders it will appeal to as well as acceptance by their family and the clinical team. It will be very important to include the young people when designing and developing any GBL system as involvement and inclusion is an important consideration that is advocated in healthcare for young people.

Our future work will progress by focussing upon requirements gathering from relevant stakeholders and will involve the following aspects:

- Assessing the acceptance of GBL in stake holders i.e. the healthcare team, patients and family. What do games mean to them and how do they see it helping and benefiting their healthcare process?

- Identifying any issues or barriers to adoption of GBL e.g. different ages and stages of adolescent development, gender and type of long term illness. How do the clinical teams feel about using GBL given the on-going debate about concerns of overuse of technology by young people?

- Identifying the requirements for GBL to assist in transitional care. What do they young people want to see?

- Identifying appropriate educational and psychological measurements to formally measure education and health outcomes as a result of using GBL.

There will be obvious limitations to the effectiveness of GBL in healthcare for young people. However the previous studies we have discussed have shown that games can be effective in engaging young people in learning to care for themselves. By their nature games are wilfully entered (Schell, 2008) and subsequently people want to participate in them. Therefore we would anticipate that by using GBL we would persuade young people to actively engage in their healthcare and build their confidence in wanting to learn to acquire the necessary skills to look after themselves.

In this chapter we have made some suggestions for frameworks for GBL which will provide clinicians with an insight into how it could be used positively in a healthcare setting and provide a basis for application to other disciplines where engagement with knowledge and skills acquisition can be challenging. 


\section{REFERENCES}

Annunziato, R.A., Emre, S., Shneider, B., Barton, C., Dugan, C.A., \& Shemesh, E. (2007). Adherence and medical outcomes in pediatric liver transplant recipients who transition to adult services. Pediatric transplantation, 11(6), 608-614.

Bingham, P.M., Bates, J.H.T., Thompson-Figueroa, J., \& Lahiri, T. (2010). A breath biofeedback computer game for children with cystic fibrosis. Clinical Pediatrics, 49(4), 337-342.

Beale, I.L., Kato, P.M., Marin-Bowling, V.M., Guthrie, N., \& Cole, S.W. (2007). Improvement in cancerrelated knowledge following use of a psychoeducational video game for adolescents and young adults with cancer. Journal Of Adolescent Health, 41(3), 263-270.

Bodenheimer, T., Chen, E., \& Bennett, H.D. (2009). Confronting the growing burden of chronic disease: can the U.S. health care workforce do the job? Health Affairs, 28(1), 64-74. doi: 10.1377/hlthaff.28.1.64.

Brown, S.J., Lieberman, D.A., Gemeny, B.A., Fan, Y.C., Wilson, D.M., \& Pasta, D.J. (1997).

Educational video game for juvenile diabetes: Results of a controlled trial. Medical Informatics, 22(1), 77-89.

Catalano, R.F., Fagan, A.A., Gavin, L.E., Greenberg, M.T., Irwin, C.E. Jr, Ross, D.A., \& Shek, D.T. (2012).Worldwide application of prevention science in adolescent health. Lancet, 379(9826), 1653-1664. doi: 10.1016/S0140-6736(12)60238-4.

Cummings, H.M., \& Vandewater, E.A. (2007). Relation of adolescent video game play to time spent in other activities. Archives of Pediatrics \& Adolescent Medicine, 161(7), 684-689.

Department of Health. (2011). Ten things you need to know about long term conditions. Retrieved from http://webarchive.nationalarchives.gov.uk/+/www.dh.gov.uk/en/Healthcare/Longtermconditions/tenthings youneedtoknow/index.htm

Durkin, K. \& Barber, B. (2002). Not so doomed: computer game play and positive adolescent development. Applied Developmental Psychology, 23(4), 373-392.

Ferguson, C.J., Miguel, C.S., Garza, A., \& Jerabeck, J.M. (2012). A longitudinal test of video game violence influences on dating and aggression: A 3-year longitudinal study of adolescents. Journal of Psychiatric Research, 46(2), 141-146.

Ferris, M.E., Harward, D.H., Bickford, K., Layton, J.B., Ferris, M.T., Hogan, S.L., Gipson, D.S., McCoy, L.P, Hooper, S.R. (2012). A clinical tool to measure the components of health-care transition from pediatric care to adult care: the UNC TR(x)ANSITION scale. Renal Failure, 34(6), 744-753.

Gentile, D.A., Choo, H., Liau, A., Sim, T., Li, D.D., Fung, D., \& Khoo, A. (2011). Pathological Video Game Use Among Youths: A Two-Year Longitudinal Stud. Pediatrics, 127(2), E319-E329.

Grundy, S.M., Benjamin, I.J., Burke, G.L., Chait, A., Eckel, R.H., Howard, B.V., Mitch, W., Smith, S.C. Jr, \& Sowers, J.R. (1999). Diabetes and cardiovascular disease: a statement for healthcare professionals from the American Heart Association. Circulation, 100(10), 1134-46. 
Hagell, A. (2012). Health implications of new technology. The association for young people's health (AYPH). Retrieved from http://www.ayph.org.uk/publications/296_RU11\%20New\%20technology\%20summary.pdf

Hagell, A., Coleman, J., \& Brooks, F. (2013). Key data on Adolescence 2013: The Latest Information and Statistics About Young People Today, Association for Young People's Health.

Kato, P.M., Cole, S.W., Bradlyn, A.S., \& Pollock, B.H. (2008). A video game improves behavioral outcomes in adolescents and young adults with cancer: A randomized trial. Pediatrics, 122(2), E305E317.

Interactive Software Federation of Europe. (2012). Industry Facts. Retrieved from http://www.isfe.eu/industry-facts.

Janssen, I., Boyce, W.F., \& Pickett, W. (2012). Screen time and physical violence in 10 to 16-year-old Canadian youth. International Journal of Public Health, 57(2), 325-331.

Janssen, N.M., \& Genta, M.S. (2000). The effects of immunosuppressive and anti-inflammatory medications on fertility, pregnancy, and lactation. Archives of Internal Medicine, 160(5), 610-619.

Lieberman, D. (1997) Interactive video games for health promotion: Effects on knowledge, self-efficacy, social support and health. In R.L. Street, W.R. Gold \& T.R. Manning (Eds.), Health promotion and interactive technology: Theoretical applications and future directions (pp103-120.). New York, NY: Routledge.

Lieberman, D.A, \& Brown, S.J. (1995). Designing interactive video games for children's health education. Studies in Health Technology and Informatics |Volume 18: Interactive Technology and the New Paradigm for Healthcare (pp 201 - 210). Amsterdam: IOS Press.

Marczewski, A. (2013). Gamification a Little on Leaderboards. Retrieved from http://marczewski.me.uk/2013/01/21/gamification-a-little-on-leaderboards/.

McDonagh, J.E., Southwood, T.R., \& Shaw KL. (2006). Growing up and moving on in rheumatology: development and preliminary evaluation of a transitional care programme for a multicentre cohort of adolescents with juvenile idiopathic arthritis. Journal of Child Health Care, 10(1), 22-42.

McDonagh, J.E. (2007). Transition of care. how should we do it? Paediatrics and Child Health, 17(12), 480-484.

Merry, S.N., Stasiak, K., Shepherd, M., Frampton, C., Fleming, T., \& Lucassen, M.F. (2012). The effectiveness of SPARX, a computerised self help intervention for adolescents seeking help for depression: randomised controlled non-inferiority trial. British Medical Journal, 18(344), e2598. doi: 10.1136/bmj.e2598.

Murray, C.J., Richards, M.A., Newton, J.N., Fenton, K.A., Anderson, H.R., Atkinson, C., Bennett, D., Bernabé, E., Blencowe, H., Bourne, R., Braithwaite, T., Brayne, C., Bruce, N.G., Brugha, T.S., Burney, P., Dherani, M., Dolk, H., Edmond, K., Ezzati, M., Flaxman, A.D., Fleming, T.D., Freedman, G., Gunnell, D., Hay, R.J., Hutchings, S.J., Ohno, S.L., Lozano, R., Lyons, R.A., Marcenes, W., Naghavi, M., Newton, C.R., Pearce, N., Pope, D., Rushton, L., Salomon, J.A., Shibuya, K., Vos, T., Wang, H., 
Williams, H.C., Woolf, A.D., Lopez, A.D., \& Davis, A. (2013). UK health performance: findings of the global burden of disease study 2010. Lancet, 381(9871), 997-1020. doi: 10.1016/S0140-6736(13)603554.

Nakhla, M., Daneman, D., To, T., Paradis, G., \& Guttmann, A. (2009). Transition to adult care for youths with diabetes mellitus: findings from a Universal Health Care System. Pediatrics, 124(6), 1134-1141.

Nash, A.A., Britto, M.T., Lovell, D.J., Passo, M.H., \& Rosenthal, S.L. (1998). Substance use among adolescents with juvenile rheumatoid arthritis. Arthritis care and research, 11(5), 391-396.

Philpott, J.R. (2011). Transitional Care in Inflammatory Bowel Disease. Gastroenterology and Hepatology, 7(1), 26-32.

Royle T. (2012). Gamification: Unlocking hidden collaboration potential. Message posted to https://www-304.ibm.com/connections/blogs/socialbusiness.

Sawicki, G.S., Lukens-Bull, K., Yin, X., Demars, N., Huang, I.C., Livingood, W., Reiss, J., Wood, D. (2011). Measuring the Transition Readiness of Youth with Special Healthcare Needs: Validation of the TRAQ_-Transition Readiness Assessment Questionnaire. Journal of Pediatric Psychology, 36(2), 160171.

Sawyer, S.M., Drew, S., Yeo, M.S., \& Britto, M.T. (2007). Adolescents with a chronic condition: challenges living, challenges treating. Lancet, 369 (9571), 1481-1489.

Sawyer, S.M., Afifi, R.A., Bearinger, L.H., Blakemore, S.J., Dick, B., Ezeh, A.C., \& Patton G.C. (2012). Adolescence: a foundation for future health. Lancet, 379(9826), 1630-1640. doi: 10.1016/S01406736(12)60072-5.

Schell, J. (2008). The Art of Game Design: A book of lenses. USA: CRC Press.

Scal, P., Garwick, A. W., \& Horvath, K. J. (2010). Making Rheumtogrow: The rationale and framework for an Internet-based health care transition intervention. International Journal of Child and Adolescent Health. 3(4), 451-461.

Shaw, K.L., Southwood, T.R., \& McDonagh, J.E. on behalf of the British Paediatric Rheumatology Group. (2004). User perspectives of transitional care for adolescents with juvenile idiopathic arthritis. Rheumatology (Oxford), 43(6), 770-778.

Stinson, J.N., Toomey, P.C., Stevens, B.J., Kagan, S., Duffy, C.M., Huber, A., Malleson, P., Mcgrath, P.J., Yeung, R.S., \& Fieldman, B.M. (2008). Asking the experts: Exploring the self-management needs of adolescents with Arthritis. Arthritis and Rheumatism, 59(1), 65-72.

Suris,J.C., Michaud, P.A., Akre, C., \& Sawyer, S.M. (2008). Health risk behaviors in adolescents with chronic conditions. Paediatrics, 122(5), e1113-8.

Suris, J.C., Akré, C., Berchtold, A., Bélanger, R.E., \& Michaud, P.A. (2010). Chronically connected? Internet use among adolescents with chronic conditions. Journal of Adolescent Health, 46(2), 200-202. 
Tackling the burden of chronic diseases in the USA. (2009). Lancet, 373(9659), 185. doi: 10.1016/S01406736(09)60048-9.

The Entertainment Software Association. (2012). Sales, demographics and usage data: Essential facts about the computer and video game industry. Retrieved from

http://www.theesa.com/facts/pdfs/ESA_EF_2013.pdf

Viner, R.M., Ozer, E.M., Denny, S., Marmot, M., Resnick, M., Fatusi, A., \& Currie C. (2012).

Adolescence and the social determinants of health. Lancet, 2012, 379(9826), 1641-1652. doi:

10.1016/S0140-6736(12)60149-4.

Wacker, A., Kaemmerer, H., Hollweck, R., Hauser, M., Deutsch, M.A., Brodherr-Heberlein, S., Eicken A., \& Hess, J. (2005). Outcome of operated and unoperated adults with congenital cardiac disease lost to follow-up for more than five years. American Journal of Cardiology, 95(6), 776-779.

World Health Organisation. (2013). 10 facts on the state of global health. Retrieved from http://www.who.int/features/factfiles/global_burden/facts/en/index.html.

World Health Organisation. (2001). The second decade: improving adolescent health and development. Geneva: World Health Organization.

Yeung, E., Kay, J., Roosevelt, G.E, Brandon, M, \& Yetman, A.T. (2008). Lapse of care as a predictor for morbidity in adults with congenital heart disease. International Journal of Cardiology, 125, 62-65.

\section{KEY TERMS \& DEFINITIONS}

Adolescent: A young person in the age range of $10-19$ years.

Birmingham Children's Hospital Adolescent Rheumatology Team transitional readiness checklists: A series of healthcare plans which were designed to assess a young patient's knowledge and acquisition of skills which are deemed important for successful transfer of their care to the adult healthcare system.

Self-efficacy: The belief in one's ability to carry out a particular task.

Self-management: The ability to manage ones daily living and affairs that are not directly related to therapy or treatment of their medical conditions.

Self-care: The ability to look after ones own healthcare.

Adherence: Complying with the clinical teams prescribed therapies for example taking the right medications at the right time.

Transitional Care: Transition addresses the medical, psychosocial as well as educational and vocational needs of the young person in an age and developmentally appropriate manner.

Chronic Medical Conditions: Medical conditions that may persist for long periods of time and even through out a person's life. 
Game Based Learning: The applications of the principles of games (fun and play) in education. In this chapter we use the term game based learning to encapsulate both the use of educational or serious computer games together with the processes used in gamification and how these can be applied to educational and healthcare settings.

Gamification: The application of game dynamics (progression, feedback and behaviours) and mechanics (the rules and actions that constitute a game) to non-game contexts. 